\title{
An insulin-dependent hypoglycaemia induced by electroacupuncture at the Zhongwan (CV12) acupoint in diabetic rats
}

\author{
S.L. Chang ${ }^{1}$, J. G. Lin ${ }^{1}$, T. C. Chi ${ }^{2}$, I. M. Liu ${ }^{2}$, J. T. Cheng ${ }^{2}$ \\ ${ }^{1}$ Institute of Chinese Medical Science, China Medical College, Taichung City, Taiwan, R. O.C. \\ ${ }^{2}$ Department of Pharmacology, College of Medicine, National Cheng Kung University, Tainan City, Taiwan, R. O. C.
}

\begin{abstract}
Summary Acupuncture at the Zhongwan acupoint has been widely used in traditional Chinese medicine to relieve symptoms of diabetes mellitus. Our study investigated the effect on plasma glucose of electroacupuncture applied at the Zhongwan acupoint in rat diabetic models. Plasma concentrations of insulin, glucagon and $\beta$-endorphin were also determined using radioimmunoassay. A decrease in plasma glucose was observed in rats after electroacupuncture (15 $\mathrm{Hz}, 10 \mathrm{~mA}$ ) for $30 \mathrm{~min}$ at the Zhongwan acupoint. This was observed in normal rats and rat models with Type II (non-insulin-dependent) diabetes mellitus. No significant effect on plasma glucose was observed in rat models with Type I (insulin-dependent) diabetes mellitus; neither the streptozotocin (STZ)induced diabetic rats nor the genetic $(\mathrm{BB} / \mathrm{W})$ rats. Further, the hypoglycaemic action of electroacupuncture stimulation disappeared in rats with insulin-resistance induced by an injection of human long-acting insulin repeated daily to cause the loss of tolbuta-
\end{abstract}

mide-induced hypoglycaemia. An insulin-related action can thus be hypothesised. This hypothesis is supported by an increase in plasma insulin-like immunoreactivity after electroacupuncture stimulation in normal rats. Participation of glucagon was ruled out because there was no change in plasma glucagonlike immunoreactivity resulting from electroacupuncture stimulation. In addition to an increase in plasma $\beta$-endorphin-like immunoreactivity, the plasma glucose lowering action of electroacupuncture stimulation at Zhongwan acupoint was abolished by naloxone in a sufficient dose to block opioid receptors. Thus we suggest that electroacupuncture stimulation at the Zhongwan acupoint induces secretion of endogenous $\beta$-endorphin which reduces plasma glucose concentration in an insulin-dependent manner. [Diabetologia (1999) 42: 250-255]

Keywords Zhongwan acupoint, electroacupuncture, $\beta$-endorphin, glucagon, insulin, radioimmunoassay.
Diabetes mellitus ranks among the top ten causes of mortality throughout the world $[1,2]$. With the rapid advancement of medicine, treatments without side effect for the long-term control of this disorder becomes important. Alternative therapies have recently received attention. Physical exercise in the control of

Received: 8 June 1998 and in final revised form: 5 October 1998

Corresponding author: Professor J.T. Cheng, Ph.D., F.C.P., Department of Pharmacology, College of Medicine, National Cheng Kung University, Tainan City, Taiwan 70101, R. O.C. Abbreviations: EA, Electroacupuncture; IRI, insulin-like immunoreactivity. diabetes has been criticised because an increase in glucagon and adrenaline secretion could raise the plasma glucose [3]. Acupuncture has been used in traditional Chinese medicine to relieve symptoms of diabetes mellitus for many years [4].

The Zhongwan acupoint is located on the abdominal wall associated with the pancreas [5]. This area contains muscle and adipose tissue, both of which are insulin sensitive tissues. Electroacupuncture (EA) is widely used in traditional Chinese medicine because it combines the effects achieved with traditional needle acupuncture with those of massage [4]. It causes a prolonged contraction of the abdominal muscle fibres and ATP expenditure in addition to an increase in blood circulation resulting in faster glu- 
cose metabolism [3]. It has been shown that EA applied at different frequencies can cause the release of endogenous opioid to activate specific receptors [6]. Opioid receptors contained in the pancreas [7] have been investigated previously to examine the role in regulation of plasma glucose concentrations [8]. In addition, $\beta$-endorphin has been shown to enhance insulin secretion [9]. Using several diabetic rat models, the aim of our study was to show EA-induced hypoglycaemia and examine whether $\beta$-endorphin could be involved in mediating this effect.

\section{Materials and methods}

Animals. Male Wistar rats, aged 8-10 weeks, were obtained from the National Cheng Kung University Animal Center. Male BioBreeding (BB/W) rats, aged 8-10 weeks, kindly donated by Dr. K. Komeda (Animal Research Center of Tokyo Medical College, Tokyo City, Japan), were used as a genetic Type I (insulin-dependent) diabetes mellitus model [10]. Streptozotocin (STZ)-induced diabetic rats, another Type I diabetic model, were prepared by intravenously injecting male Wistar rats aged 8-10 weeks with STZ $(60 \mathrm{mg} / \mathrm{kg})$ after they had fasted for 3 days. A model of Type II (non-insulin-dependent) diabetes mellitus was prepared by an intraperitoneal injection (i.p.) of STZ $(60 \mathrm{mg} / \mathrm{kg})$ given to neonatal male Wistar rats (within 2 days of birth) as described previously [11]. Rats with hyperglycaemia in addition to symptoms of polyuria or other symptoms or both were considered as diabetic. Insulin-resistance was also induced in rats aged 8 weeks by i.p. injections of long-acting human insulin (Monotard, Novo Nordisk, Bagsvaard, Denmark) at $0.5 \mathrm{IU} / \mathrm{kg}$ three times daily.

Zhongwan Acupoint. As described in a previous report [5], one unit in acupuncture is defined as 1/14 of the distance between the top of xiphoid process and the upper crest of pubis bond. The Zhongwan acupoint is oriented vertically on the Ren meridium along the median of the abdomen and horizontally 9 units above the upper crest of the pubis bond. The Gwanyuan acupoint is oriented vertically on the Ren meridium along the median of the abdomen and horizontally 2 units above the upper crest of the pubis bond (Fig. 1). Two points were also stimulated as a non-acupoints control; each point was inserted in parallel at 3 units from the Zhongwan acupoint or the Gwanyuan acupoint, respectively.

Electroacupuncture (EA). After adjusting the frequency and amperage of the electroacupuncture apparatus, a needle of 0.5 inch length (Chian-Huei Chinese Acupuncture Instrument Co., Taipei, Taiwan) was inserted into the muscle layer at the selected acupoint to a depth of $2 \mathrm{~mm}$. The positive charge was introduced at the Zhongwan acupoint and the negative charge was connected to the Gwanyuan acupoint. Each stimulation session lasted 30 min (Han's Healthronics Likon, Taipei, Taiwan). Electrostimulation was carried out at the frequencies of $0,2,15$ and $100 \mathrm{~Hz}$ in dose-finding experiments preceeding this study. From the preliminary experiments, we found that the $15 \mathrm{~Hz}$ frequency elicited the most pronounced reduction in plasma glucose in rats. Thus, electrostimulation was at 15 $\mathrm{Hz}$ in this study.

Diabetic rats were divided into experimental and control groups. They were treated with naloxone $(1 \mathrm{mg} / \mathrm{kg}$ body weight) via an injection into the femoral vein under anaesthe- sia with pentobarbital $(30 \mathrm{mg} / \mathrm{kg}$, i.p.). Blood samples were taken from the femoral vein $30 \mathrm{~min}$ before the injection of naloxone. The experimental group received EA stimulation $(15 \mathrm{~Hz}, 10 \mathrm{~mA})$ for $30 \mathrm{~min}$ and the changes were compared with the group that received stimulation at a non-acupoint. Then, another blood sample was taken from the rats for determination of plasma glucose to calculate hypoglycaemic activity.

Laboratory determinations. After fasting $12 \mathrm{~h}$ or more, rats were anaesthetized with pentobarbital $(30 \mathrm{mg} / \mathrm{kg}$, i.p.). Then, a blood sample $(0.5 \mathrm{ml})$ was taken from the femoral vein and placed in an Eppendorf tube containing 10 IU heparin. After electrostimulation, another blood sample $(0.5 \mathrm{ml})$ was obtained from the femoral vein. Blood samples were then centrifuged at $13000 \mathrm{rpm}$ for $3 \mathrm{~min}$ and an aliquot (15 $\mu \mathrm{l})$ of plasma was added to $1.5 \mathrm{ml}$ of Glucose Kit Reagent (Biosystems S. A., Barcelona, Spain) and incubated at $37^{\circ} \mathrm{C}$ in a water bath (Yamato-BT-25, Tokyo, Japan) for $10 \mathrm{~min}$. The concentration of plasma glucose was then estimated via an analyser (Quik-Lab, Ames, Miles Inc., Elkhart, Ind., USA) run in duplicate.

The plasma peptides were determined by radioimmunoassay (RIA) as described previously [12]. Assay of plasma insulin [13] or plasma glucagon [14] was by commercial kit from Linco Res. Inc. (St. Charles, Mo., USA). The plasma $\beta$-endorphin concentration was also estimated using a commercial RIA kit from Pennisula Lab. Inc. (Belmont, Calif., USA) [15]. Determination of plasma peptides was made in samples from STZinduced diabetic rats, Type II diabetic rats and Wistar rats except that RIA of insulin was not done in the plasma from STZ-induced diabetic rats. In brief, an aliquot (100 $\mu \mathrm{l})$ of plasma was placed into test tubes. Samples from an individual were analysed in triplicate at the same time. The values obtained were indicated as ng of peptide-like immunoreactivity per ml of plasma. Naloxone or other test compounds used in our study did not affect the binding of peptide with antibodies.

Calculation and statistical analysis. The hypoglycaemic activity was determined in fasted rats that received EA stimulation under anaesthesia. Results were calculated as the percentage decrease of the initial value according to the formula: $(\mathrm{Gi}-\mathrm{Gt}) \times 100 / \mathrm{Gi}$ where Gi was the initial glucose concentration and Gt was the plasma glucose concentration after treatment with EA.

Data are expressed as means \pm SEM for the number $(n)$ of animals in the group. Repeated measurements by analysis of variance (ANOVA) were done to analyse the changes in plasma glucose and other variables. Dunnett range post-hoc comparisons were used to determine the source of significant differences where appropriate. $P$ less than 0.05 was considered statistically significant.

\section{Results}

Effect on plasma glucose. In this study, four kinds of rats aged 10 weeks or more were used for EA-stimulation at the Zhongwan acupoint; the location of this acupoint is indicated in Fig. 1. As to basal plasma glucose, hyperglycaemia was observed in STZ-induced diabetic rats $(24.7 \pm 1.2 \mathrm{mmol} / \mathrm{l} ; n=7)$ and $\mathrm{BB} / \mathrm{W}$ rats $(16.3 \pm 3.6 \mathrm{mmol} / 1 ; n=8)$ whereas Type II diabetic rats $(7.5 \pm 0.2 \mathrm{mmol} / \mathrm{l} ; n=8)$ had slightly higher concentrations of glucose $(p<0.05)$ than normal rats 
Table 1. Plasma glucose and peptides in rats receiving electroacupuncture (EA) stimulation

\begin{tabular}{|c|c|c|c|c|}
\hline & \multicolumn{2}{|c|}{ Type II diabetic rats } & \multicolumn{2}{|l|}{ Normal rats } \\
\hline & Before & After & Before & After \\
\hline $\begin{array}{l}\text { Plasma Glucose }(\mathrm{mmol} / \mathrm{l}) \\
\text { EA at Zhongwan acupoint } \\
\text { EA at non-acupoint }\end{array}$ & $\begin{array}{l}7.6 \pm 0.6 \\
7.1 \pm 1.0\end{array}$ & $\begin{array}{l}6.0 \pm 0.5^{b} \\
6.6 \pm 0.9\end{array}$ & $\begin{array}{l}6.4 \pm 1.3 \\
5.9 \pm 0.4\end{array}$ & $\begin{array}{l}5.3 \pm 1.3^{b} \\
6.1 \pm 0.5\end{array}$ \\
\hline $\begin{array}{l}\text { Plasma Insulin (pmol/l) } \\
\text { EA at Zhongwan acupoint } \\
\text { EA at non-acupoint }\end{array}$ & $\begin{array}{l}302.2 \pm 3.8 \\
297.3 \pm 4.2\end{array}$ & $\begin{array}{l}514.4 \pm 3.3^{\mathrm{b}} \\
300.6 \pm 4.9\end{array}$ & $\begin{array}{l}223.8 \pm 2.2 \\
202.1 \pm 3.5\end{array}$ & $\begin{array}{l}465.9 \pm 4.3^{\mathrm{b}} \\
168.7 \pm 5.4\end{array}$ \\
\hline $\begin{array}{l}\text { Plasma Glucagon (ng/l) } \\
\text { EA at Zhongwan acupoint }\end{array}$ & $29.5 \pm 5.1$ & $31.0 \pm 4.4$ & $28.9 \pm 3.0$ & $25.8 \pm 3.8$ \\
\hline $\begin{array}{l}\text { Plasma } \beta \text {-endorphin (pmol/l) } \\
\text { EA at Zhongwan acupoint } \\
\text { EA at non-acupoint }\end{array}$ & $\begin{array}{l}2.8 \pm 0.4 \\
3.2 \pm 0.4\end{array}$ & $\begin{array}{l}4.3 \pm 0.6^{\mathrm{a}} \\
3.1 \pm 0.4\end{array}$ & $\begin{array}{l}2.3 \pm 0.3 \\
2.0 \pm 0.3\end{array}$ & $\begin{array}{l}4.0 \pm 0.1^{\mathrm{a}} \\
2.2 \pm 0.4\end{array}$ \\
\hline
\end{tabular}

Values of means \pm SEM were obtained from 8 animals in each group except the group for electroacupuncture (EA)-stimulation at non-acupoint that were calculated from 7 animals $(n=7)$.

${ }^{\mathrm{a}} p<0.05$ and ${ }^{\mathrm{b}} p<0.01$ vs values at before, respectively

$(6.34 \pm 0.5 \mathrm{mmol} / \mathrm{l} ; n=8)$. After EA stimulation at the Zhongwan acupoint, a lowering of plasma glucose was observed in these matured rats aged 10 weeks old or older. EA-induced hypoglycaemia was observed in Type II diabetic rats and normal Wistar rats (Table 1). Changes were not significant (NS), however, in $\mathrm{BB} / \mathrm{W}$ rats (from $16.3 \pm 3.6 \mathrm{mmol} / \mathrm{l}$ to $16.1 \pm$ $3.6 \mathrm{mmol} / \mathrm{l} ; n=8$ ) or the STZ-induced diabetic rats (from $24.7 \pm 1.2 \mathrm{mmol} / 1$ to $23.6 \pm 1.1 \mathrm{mmol} / \mathrm{l} ; n=7$ ) after EA-stimulation.

The specific action of this EA stimulation at the Zhongwan acupoint was confirmed by a similar EA stimulation at non-acupoint location. Plasma glucose concentrations in Wistar or Type II diabetic rats receiving EA stimulation at the non-acupoint were not significantly influenced (NS). After EA stimulation at the Zhongwan acupoint, the hypoglycaemic activity in Type II diabetic rats was $21 \pm 2 \%(n=8)$ which was appreciably $(p<0.01)$ different from the hypoglycaemic activity of non-acupoint stimulation $(3 \pm 15 \% ; n=8)$. A similar result was obtained in Wistar rats; the decrease of plasma glucose was higher $(p<0.01)$ in rats receiving EA stimulation at the Zhongwan acupoint than those receiving non-acupoint stimulation. Moreover, hypoglycaemia-induced by EA stimulation in Type II diabetic rats or normal rats was reversed to normal within $30 \mathrm{~min}$ after the termination of electrostimulation.

Effect on plasma insulin. To examine the role of insulin in EA-induced hypoglycaemia in rats, plasma insulin concentrations were measured. Insulin-like immunoreactivity (IRI) in plasma from the normal rats was greatly increased by EA stimulation at the Zhongwan acupoint compared with the basal concentration. Plasma IRI was not, however, modified (NS) by the non-acupoint stimulation more than that by control non-acupoint stimulation (Table 1). Further, the basal concentration of IRI in plasma from Type
II diabetic was higher than that of healthy Wistar rats $(p<0.05$, Table 1$)$.

Failure of the action of EA-stimulation in rats with insulin-resistance. After intraperitoneal (i.p.) injection of long-acting human insulin at $0.5 \mathrm{IU} / \mathrm{kg}$ three times daily, an increase $(p<0.01)$ of plasma glucose from $4.3 \pm 0.4 \mathrm{mmol} / \mathrm{l}$ to $5.8 \pm 0.3 \mathrm{mmol} / \mathrm{l}(n=9)$ was observed in young Wistar rats (8-weeks old) within 15 days. An i.p. injection of $10 \mathrm{mg} / \mathrm{kg}$ tolbutamide given to these young normal rats (8-weeks old) produced a considerable $(p<0.05)$ lowering of plasma glucose from $4.3 \pm 0.4 \mathrm{mmol} / \mathrm{l}$ to $3.2 \pm 0.4 \mathrm{mmol} / \mathrm{l}$ $(n=9)$. The hypoglycaemic response to tolbutamide decreased gradually in rats that received daily injections of long-acting insulin and a lack of response to this drug was observed 16 days later (Fig. 2); the plasma glucose concentration was modified only from $5.8 \pm 0.8 \mathrm{mmol} / 1$ to $5.6 \pm 0.7 \mathrm{mmol} / 1(n=9)$ with the same dose of tolbutamide (NS). A decrease of EA-induced hypoglycaemia was also observed in these rats that received long-acting insulin in a similar manner to the response to tolbutamide on day 16 (Fig. 2); the plasma glucose was unchanged (NS) from $5.8 \pm$ $1.2 \mathrm{mmol} / \mathrm{l}$ to $5.7 \pm 1.0 \mathrm{mmol} / \mathrm{l}(n=8)$. When the injection of human insulin was stopped in the insulinresistant rats, the plasma glucose concentration returned to normal within 7 days (data not shown; $n=8)$. Recovery from insulin-resistance was further confirmed by the return of the hypoglycaemic action of tolbutamide $(10 \mathrm{mg} / \mathrm{kg})$ to normal concentrations in these rats (data not shown; $n=8$ ).

Effect on plasma glucagon concentration. Plasma glucagon concentrations were also determined using commercial RIA kits. Basal glucagon-like immunoreactivity was higher $(p<0.01)$ in plasma from STZ-induced diabetic rats $(42.8 \pm 4.2 \mathrm{ng} / \mathrm{l} ; n=7)$ than that from Type II diabetic rats or normal ones. 


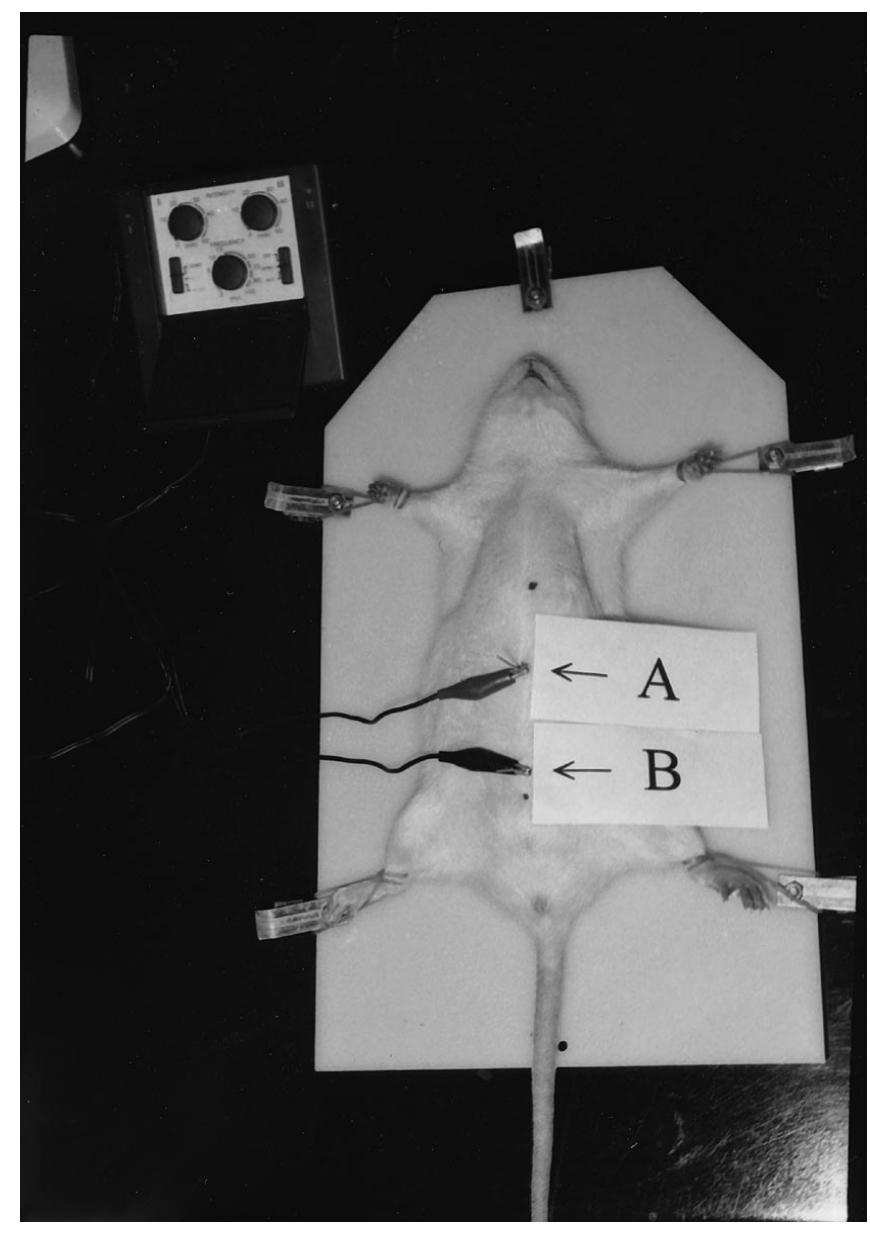

Fig. 1. Diagram of the position of Zhongwan acupoint for electroacupuncture (EA) in rats. Point $A$ indicates the location of the Zhongwan acupoint and point $\mathrm{B}$ shows the location of the Gwanyuan acupoint

No difference (NS) was observed, however, in the rats receiving EA stimulation at the Zhongwan acupoint compared with basal concentrations (Table 1).

Influence of naloxone. Mediation of opioid receptors in the hypoglycaemic action induced by EA-stimulation was investigated using the antagonist naloxone. In the presence of naloxone $(1 \mathrm{mg} / \mathrm{kg}$, i. v. $)$, basal plasma glucose was not modified $(7.6 \pm 1.8 \mathrm{mmol} / \mathrm{l}$ vs $7.6 \pm 1.4 \mathrm{mmol} / \mathrm{l} ; n=6$ ), the hypoglycaemic action of EA-stimulation was abolished in Type II diabetic rats; plasma glucose became $7.7 \pm 1.2 \mathrm{mmol} / \mathrm{l}(n=6)$ and hypoglycaemic activity was decreased to $1 \pm 5 \%$ $(n=6)$ only. Otherwise, the increase of plasma insulin-like immunoreactivity (IRI) and the lowering of plasma glucose in normal Wistar rats by this EA stimulation at the Zhongwan acupoint were blocked by naloxone. After a similar treatment with naloxone, plasma IRI in normal rats receiving EA stimulation became $210.4 \pm 3.2 \mathrm{pmol} / \mathrm{l}(n=8)$ which was not significantly different from the control $(208.8 \pm 4.2$ $\mathrm{pmol} / \mathrm{l} ; n=8)$. Also, plasma glucose became $6.2 \pm$

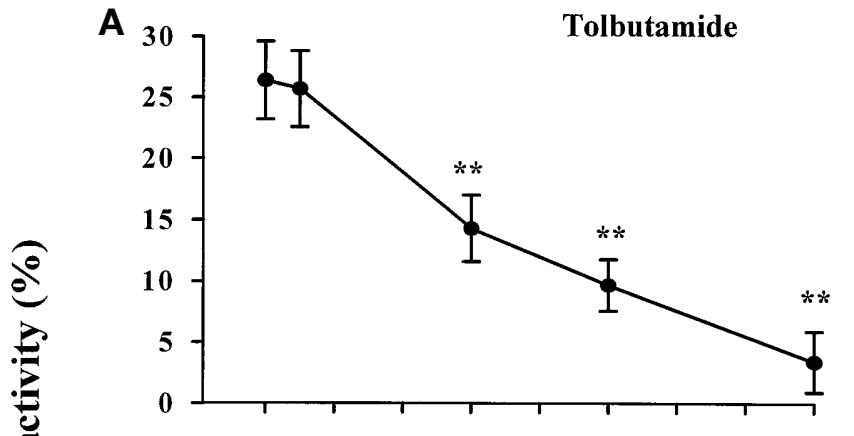

B

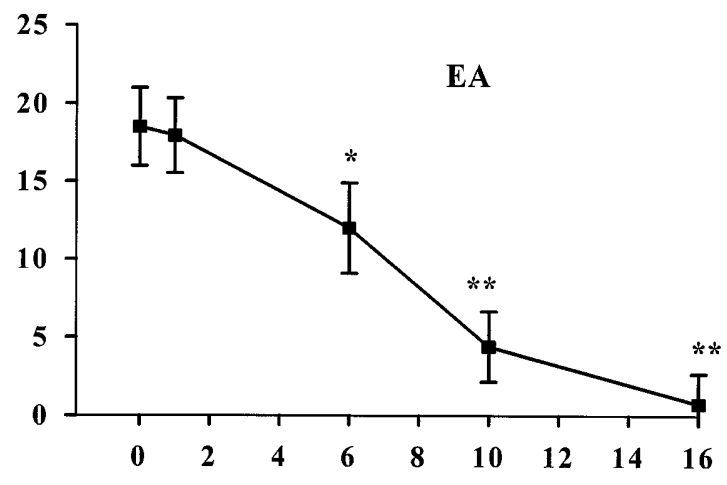

Days

Fig.2A, B. Hypoglycaemia induced by electroacupuncture (EA) at Zhongwan acupoint in rats with insulin-resistance. Wistar rats received an intraperitoneal injection (i. p.) of long-acting human insulin (Monotard HM; $0.5 \mathrm{IU} / \mathrm{kg}$ ) three times daily. Changes in hypoglycaemic activity (\%) of tolbutamide $(10 \mathrm{mg} / \mathrm{kg}$, i.p. $)$ are indicated in $\mathbf{A}$ and changes in hypoglycaemic activity induced by EA stimulation are indicated in B. Values (means \pm SEM) were obtained from 8-11 experiments. ${ }^{*} p<0.05,{ }^{* *} p<0.01$ vs day 0

$0.2 \mathrm{mmol} / \mathrm{l}(n=6)$ which was no different from the control $(6.3 \pm 0.3 \mathrm{mmol} / \mathrm{l} ; n=6)$.

Effect on plasma $\beta$-endorphin concentration. An increase in plasma $\beta$-endorphin-like immunoreactivity was obtained in rats after EA stimulation at the Zhongwan acupoint using paired comparison with basal concentrations (Table 1). This increase of plasma $\beta$-endorphin by EA stimulation was also observed in Type II diabetic rats. Plasma $\beta$-endorphin was not modified, however, in rats receiving non-acupoint stimulation for both the Type II diabetic and Wistar rats (Table 1) although the basal concentration of plasma $\beta$-endorphin seemed higher in Type II diabetic rats (Table 1). Furthermore, plasma $\beta$-endorphin in STZ-induced diabetic rats $(n=8)$ was also raised by EA stimulation at the Zhongwan acupoint from $3.9 \pm 0.7 \mathrm{pmol} / 1$ to $5.4 \pm 1.3 \mathrm{pmol} / \mathrm{ml}(p<0.05)$. This increase in plasma $\beta$-endorphin was not observed in STZ-induced diabetic rats receiving EA stimulation at non-acupoint; plasma $\beta$-endorphin was from $3.8 \pm 0.7 \mathrm{pmol} / 1$ to $3.7 \pm 0.4 \mathrm{pmol} / \mathrm{l}(\mathrm{NS})$. 


\section{Discussion}

In this study, we found that EA at the Zhongwan acupoint can lower plasma glucose concentrations in rats with or without hyperglycaemia. From the preliminary experiments, EA stimulation at a frequency of $15 \mathrm{~Hz}$ was found to be the most effective. Hypoglycaemia induced by such EA stimulation was transient and plasma glucose returned to normal within 30 min after EA stimulation. A similar EA stimulation at the nonacupoint location failed to produce hypoglycaemia in both Type II diabetic and Wistar rats (Table 1). It can be considered that the hypoglycaemic effect is a specific response to the EA at the Zhongwan acupoint and is not due to a general stimulation of muscle.

In our study, rats were treated under anaesthesia. Previous studies have reported that animals anaesthetized with pentobarbital for $30 \mathrm{~min}$ after a period of fasting showed no effect on the plasma concentrations of glucose, insulin or glucagon [16]. Any changes detected after the animal is anaesthetized should therefore be the direct result of treatment. Thus, we used anaesthetized rats using the same procedure.

In different comparative studies using diabetic models, EA stimulation induced a pronounced reduction in plasma glucose concentration in normal rats and Type II diabetic rats but had no influence in STZ-induced diabetic rats or genetic diabetic BB/W rats. This indicates that EA stimulation at the Zhongwan acupoint elicits a pronounced reduction in plasma glucose concentrations in animal models with better pancreatic function. An insulin-dependent action can thus be considered. The plasma concentration of insulin measured by RIA supported the mediation of insulin in EA stimulation-induced hypoglycaemia because EA stimulation at the Zhongwan acupoint raised plasma insulin (IRI) in rats (Table 1). Moreover, EA stimulation-induced hypoglycaemia was not seen in rats with insulin-resistance induced by repeated injection of insulin, which was confirmed by the loss of tolbutamide-induced hypoglycaemia (Fig. 2). Based on the report that tolbutamide-induced hypoglycaemia occurs through stimulation of endogenous insulin release [17], the loss of tolbutamide-induced hypoglycaemia can be interpreted as the development of insulin resistance. Similar animal models have been described previously [18]. There is no doubt that secretion of endogenous insulin is a mediator in this EA stimulation-induced hypoglycaemia. It also indicates that EA stimulation at the Zhongwan acupoint would be more effective in patients whose pancreatic cells still retain partial insulin secretion. Although the acupoints in rats are not really known, it is fortuitous that they appear to correspond with those of humans for this hypoglycaemic action.

Electroacupuncture stimulation at the Zhongwan acupoint can reduce plasma glucose concentration in Type II diabetic rats but not in rats with insulin resis- tance induced by repeated injection of insulin. This is possibly due to the difference between two animal models. It has been mentioned that a decrease of insulin sensitivity was observed in Type II diabetic rats $[11,19]$. Multiple mechanisms have, however, been documented to be responsible for insulin resistance [20]. Thus, resistance to insulin-induced hypoglycaemia in this study by daily injection of long-acting human insulin seems different from that of Type II diabetic rats. Nevertheless, endogenous glucagon concentrations cannot explain this difference because EA stimulation did not modify plasma glucagon concentrations in rats. The basal concentrations of plasma glucagon were similar in Type II diabetic and normal rats although a higher concentration of plasma glucagon was obtained in STZ-induced diabetic rats. The lack of a major role of plasma glucagon in hyperglycaemia could be due to the diminished response of glucagon observed in STZ-induced diabetic rats [14]. No changes in plasma glucagon were, however, also obtained in Type II diabetic rats and normal rats receiving this EA stimulation. These findings ruled out the role of glucagon in hypoglycaemia-induced by EA stimulation at the Zhongwan acupoint.

It has been mentioned that EA applied at different frequencies can cause the release of endogenous opioid to activate specific receptors [6]. Opioid receptors contained in the pancreas $[7,8]$ have widely been investigated for a role in the regulation of plasma glucagon concentrations [21, 22]. We found that naloxone, at concentrations sufficient to block opioid receptors, abolished the lowering of plasma glucose by EA stimulation. Blockade of EA stimulation-induced increase of plasma insulin was also seen in rats receiving similar treatment with naloxone. Naloxone is often used as a tool in eliciting relations between $\beta$-endorphin and plasma glucose homeostasis [23, 24]. In diabetic patients, $\beta$-endorphin stimulates insulin secretion [19]. The plasma concentration of $\beta$-endorphin measured by RIA was also raised after this EA stimulation at the Zhongwan acupoint in rats. Taken together, it can be considered that an increase in plasma $\beta$-endorphin by this EA stimulation in rats could enhance the secretion of insulin to produce hypoglycaemia. This view is further supported by our findings that increase of plasma $\beta$-endorphin by this EA stimulation was also obtained in STZ-induced diabetic rats without appreciable hypoglycaemia due to the absence of endogenous insulin. All the results are in agreement with the hypothesis that $\beta$-endorphin is involved in plasma glucose homeostasis [21,22].

In conclusion, we suggest that EA stimulation at the Zhongwan acupoint could induce the secretion of $\beta$-endorphin to produce hypoglycaemia in an insulin-dependent manner in rats.

Acknowledgements. We thank Dr. K. Komeda (Animal Reserach Center of Tokyo Medical College, Tokyo City, Japan) 
for the kind supply of $\mathrm{BB} / \mathrm{W}$ rats that were maintained in the animal center of the National Cheng Kung University Medical College. The technical assistance of Miss S. M. Dai is also appreciated.

\section{References}

1. Liu YC, Lee YJ (eds) (1992) Treatment of diabetes mellitus using Chinese traditional medicine. Jyr Yuan Book Store, Taipei, pp 1-2

2. Kuang AK, Chen JL, Ho JS (eds) (1992) Diabetes Research. Jyr Yin Publishing, Taipei, pp 1-2, 294-295

3. Guyton AC (ed) (1981) The Textbook of Medical Physiology. 6th edn. WB Saunders, New York, pp 131, 841, 967

4. Kao LY (1993) Case report of physical therapy for patients with diabetes mellitus. An-mo and Daul-in (in Chinese) 4: 44

5. Yan JG (ed) (1990) Anatomical atlas of acupoints. Shanghai Scientific Publishers, Shanghai, p 161

6. Chen XH, Han JS (1992) Analgesia induced by electroacupuncture of different frequencies is mediated by different types of opioid receptors: another cross-tolerance study. Behav Brain Res 47: 143-149

7. Khawaja XZ, Green IC, Thorpe JR, Titheradge MA (1990) The occurrence and receptor specificity of endogenous opioid peptides within the pancreas and liver of rats in comparison with the brain. Biochem J 267: 233-240

8. Bruni JF, Watkins WB, Yen SS (1979) $\beta$-endorphin in the human pancreas. J Clin Endocrinol Metab 49: 649-651

9. Curry DL, Bennet LL, Li CH (1987) Stimulation of insulin secretion by $\beta$-endorphins (1-27 \& 1-31). Life Sci 40: 2053-2008

10. Raymond A, Curtis SB, Crisholm CB, Gaba NRA, Campos RV, Brown JC (1991) Insulin secretion and islet endocrine cell content at onset and during the early stages of diabetes in the BB rat: effect of the level of glycemic control. Can J Physiol Pharmacol 69: 1230-1236

11. Levy J, Gavin JR III, Fausto A, Gingerich RL, Aviolo LV (1984) Impaired insulin action in rats with non-insulin-dependent diabetes. Diabetes 33: 901-906
12. Dwenger A (1984) Radioimmunoassay: An Overview. J Clin Biochem 22: 883

13. Morgan CR, Lazarow A (1963) Immunoassay of insulin: two antibody system. Plasma insulin levels in normal, subdiabetic and diabetic rat. Diabetes 12: 115-121

14. Nadeau A, Rousseau-Migneron S, Tancrede G, Jobidon C, Trudel D (1985) Diminished glucagon response to epinephrine in physically trained diabetic rats. Diabetes 34: 1278-1282

15. Farrell PA, Sonne B, Mikines K, Glbo H (1988) Stimulatory role for endogenous opioid peptides on postexercise insulin secretion in rat. J Appl Physiol 65: 744-749

16. Johansen O, Vaaler S, Jorde R, Reikeras O (1994) Increased plasma glucose levels after hypnorm anaesthesia, but not after pentobarital anaesthesia in rat. Lab Anim 28: 244-248

17. Hinds A, Sheehan AG, Parsons HG (1995) Tolbutamide causes a modest increase in insulin secretion in cystic fibrosis patients with impaired glucose tolerance. Metabolism 44: $13-18$

18. Chi TC, Liu IM, Cheng JT (1998) A simple and rapid model of insulin-resistance in Wistar rats. Chin Pharm J 50: 113-121

19. Prince MJ, Tsai P, Olefsky JM (1981) Insulin binding, internalization, and insulin receptor regulation in fibroblasts from type II, non-insulin-dependent diabetic subjects. Diabetes 30: 596-600

20. Youngren JF, Goldfine ID (1997) The molecular basis of insulin resistance. Sci Med 3: 18-27

21. Ramabadran K, Bansinath M (1990) Glucose homeostasis and endogenous opioid peptides. Int $\mathrm{J}$ Clin Pharmacol Ther 28: 89-98

22. Feldman M, Kiser RS, Unger RH, Li CH (1983) $\beta$-endorphin and the endocrine pancreas: Studies in healthy and diabetic human beings. N Engl J Med 308: 349-353

23. Hickey MS, Trappe SW, Blostein AC, Edwards BA, Goodpaster B, Craig BW (1994) Opioid antagonism alters blood glucose homeostasis during exercise in humans. J Appl Physiol 76: 2452-2460

24. Locatelli A, Spotti D, Caviezel F (1985) The regulation of insulin and glucagon secretion by opiates: a study with naloxone in healthy humans. Acta Diabetol 22: 25-31 